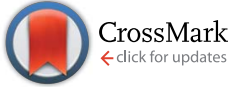

Cite this: RSC Adv., 2017, 7, 15390

\title{
Facile synthesis of mesoporous detonation nanodiamond-modified layers of graphitic carbon nitride as photocatalysts for the hydrogen evolution reaction $\uparrow$
}

\author{
Yasir A. Haleem, ${ }^{a}$ Qun He, ${ }^{a}$ Daobin Liu, ${ }^{a}$ Changda Wang, ${ }^{a}$ Weiyu $\mathrm{Xu}^{\text {a }}{ }^{\text {Wei Gan, }}{ }^{a}$ \\ Yu Zhou, ${ }^{a}$ Chuangqiang Wu, ${ }^{a}$ Yanwei Ding ${ }^{\mathrm{b}}$ and Li Song ${ }^{\star a}$
}

\begin{abstract}
The hydrogen evolution reaction (HER) may contribute substantially to energy resources in the future through solar energy conversion. In this study, mesoporous graphitic carbon nitride $\left(\mathrm{g}-\mathrm{C}_{3} \mathrm{~N}_{4}\right)$ layers modified by detonation nanodiamond (DND) were synthesized by condensation from urea to obtain a robust and efficient hybrid ( $\mathrm{g}-\mathrm{C}_{3} \mathrm{~N}_{4}-\mathrm{DND}$ ) photocatalyst for the HER. Our characterizations revealed that no significant structural changes occurred in $\mathrm{g}-\mathrm{C}_{3} \mathrm{~N}_{4}$ during the synthesis of the $\mathrm{g}-\mathrm{C}_{3} \mathrm{~N}_{4}-\mathrm{DND}$ hybrid. Compared with pure $\mathrm{g}-\mathrm{C}_{3} \mathrm{~N}_{4}$, hydrogen production increased by almost $50 \%$ when using the hybrid photocatalyst due to the synergetic effect of the enhanced charge transfer, high surface area and low recombination rate of the photogenerated charge carriers.
\end{abstract}

Received 21st February 2017

Accepted 23rd February 2017

DOI: $10.1039 / c 7 r a 02178 j$

rsc.li/rsc-advances

performance under visible light. ${ }^{6}$ The insufficient charge sepa-

\section{Introduction}

Solar energy is the only form of energy that is abundant and cheap. Therefore, from the last few decades, scientists around the world are trying to utilize this energy. One way of harnessing this energy is splitting water into its constituents using photocatalysts and storing the produced hydrogen, which is a clean source of energy. ${ }^{1}$ In the past two decades, a lot of study has been carried out on photocatalysts and this is still ongoing. The demand for photocatalysts for the hydrogen evolution reaction (HER) is very high because they use sunlight and water for the production of hydrogen. Although using solar energy and water for the HER is a cheap way of producing hydrogen, the use of metal-based photocatalysts increases the cost. Hence, to reduce costs, currently, researchers are moving towards metal-free photocatalysts for the HER..$^{2-4}$ However, to facilely obtain a stable and efficient photocatalyst is still a challenge in practical applications. ${ }^{5}$ Semiconductors are widely used as photocatalysts for the HER, but they have a large band gap and low

${ }^{a}$ National Synchrotron Radiation Laboratory, CAS Centre for Excellence in Nanoscience, University of Science and Technology of China, Hefei-230029, Anhui, P. R. China. E-mail: song2012@ustc.edu.cn; Fax: +86-551-6360-2102; Tel: +86-5516360-2102

${ }^{b}$ Hefei National Laboratory for Physical Sciences at Microscale, University of Science and Technology of China, Hefei, Anhui 230026, China

$\dagger$ Electronic supplementary information (ESI) available: Experimental details, TGA of DND, FTIR spectra, TEM images, photograph of synthesized samples, AFM measurements, XPS survey spectra, $\mathrm{N}_{2}$-sorption isotherms, pore size distribution curves, plot of $h v$ vs. $(A h v)^{2}$, and XRD spectrum. See DOI: 10.1039/c7ra02178j ration ability of photocatalysts is also an issue and this is the main limitation for using photocatalysts for the HER. ${ }^{7}$ In the last decade, carbon nitride has been extensively used as a photocatalyst for splitting water into hydrogen and oxygen. However, there are some factors that limit the use of carbon nitride as a photocatalyst, namely, the high recombination rate of the photogenerated electron-hole pairs, low specific surface area, and limited visible-light absorption. ${ }^{8}$ Doping of the nanostructures and copolymerization techniques have been employed to address these issues. ${ }^{9} \mathrm{Xu}$ et al. ${ }^{10}$ prepared graphitic carbon nitride $\left(\mathrm{g}-\mathrm{C}_{3} \mathrm{~N}_{4}\right)$ sheets of a single atomic layer by a simple chemical exfoliation method and observed an enhanced photocatalytic activity for hydrogen production, pollutant decomposition, and photocurrent generation. Jiang et al. ${ }^{9}$ modified the g- $\mathrm{C}_{3} \mathrm{~N}_{4}$ sheets with $\mathrm{Ag}_{3} \mathrm{PO}_{4}$ nanoparticles, which led to an enhanced degradation of Rhodamine $\mathrm{B}$ under visible light irradiation by decreasing the recombination rate of photoinduced electron-hole pairs. Though some efforts have been made, it is still highly desirable to develop new scalable synthetic methods for optimizing the hybridization of g- $\mathrm{C}_{3} \mathrm{~N}_{4}$ for highly efficient photocatalysts. In this study, we selected detonation nanodiamond (DND) as the modifying agent to produce a g- $\mathrm{C}_{3} \mathrm{~N}_{4}-\mathrm{DND}$ hybrid photocatalyst with an efficient catalytic activity in the hydrogen evolution reaction. DND is one of several carbon nanostructures with great potential in a variety of applications. ${ }^{11}$ Currently, it is being produced in bulk quantities with a primary particle size of 3-5 nm. ${ }^{12,13}$ Moreover, DND has a highly interactive and tailorable surface. Molecules are tightly packed forming clusters that are difficult to 
disintegrate. ${ }^{14}$ Excellent mechanical and thermal properties along with its tailorable surface make DND a highly suitable modifying agent. ${ }^{15-17}$ The idea behind the use of DND as a modifying agent is based on DND acting as a template to synthesize mesoporous $\mathrm{g}-\mathrm{C}_{3} \mathrm{~N}_{4}$ layers, owing to its small size and excellent mechanical properties.

In our experiments, the $\mathrm{g}-\mathrm{C}_{3} \mathrm{~N}_{4}$-DND hybrid was prepared by the direct incorporation of DND into urea and a deionized water solution, and during condensation, DND not only coupled to the layers of $\mathrm{g}-\mathrm{C}_{3} \mathrm{~N}_{4}$, but also made them mesoporous. The thermogravimetric analysis of DND shows that it can sustain temperatures up to $620{ }^{\circ} \mathrm{C}$ (see Fig. $\mathrm{S} 1 \dagger$ ) in air while the temperature for the synthesis of $\mathrm{g}-\mathrm{C}_{3} \mathrm{~N}_{4}$ is $550{ }^{\circ} \mathrm{C}$ (see $\mathrm{ESI} \dagger$ for materials and methods). The photocatalytic activity of the g$\mathrm{C}_{3} \mathrm{~N}_{4}$-DND hybrid was significantly enhanced as compared to that of pure g- $\mathrm{C}_{3} \mathrm{~N}_{4}$. This study provides an insight about the role of $g-\mathrm{C}_{3} \mathrm{~N}_{4}$ as a photocatalyst for the HER as well as potential applications of DND in solar energy conversion.

\section{Results and discussion}

The structure of $\mathrm{g}-\mathrm{C}_{3} \mathrm{~N}_{4}$ and the g- $\mathrm{C}_{3} \mathrm{~N}_{4}-\mathrm{DND}$ hybrid were determined by X-ray diffraction (XRD) and X-ray absorption near edge structure (XANES). In Fig. 1a, the peaks at around $13.1^{\circ}$ and $27.7^{\circ}$ indicate the diffraction from the (100) and (002) planes in $\mathrm{g}-\mathrm{C}_{3} \mathrm{~N}_{4} \cdot{ }^{18}$ The (100) plane can be attributed to the packing of the tri-s-triazine units, whereas the (002) plane can be attributed to the interlayer stacking of the aromatic segments. ${ }^{19}$ The XRD pattern of $\mathrm{g}^{-} \mathrm{C}_{3} \mathrm{~N}_{4}-\mathrm{DND}(0.4 \mathrm{wt} \%)$, shown in Fig. 1 b, contains peaks at $13.25^{\circ}$ and $27.32^{\circ}$, corresponding to the (100) and (002) planes, respectively. Both XRD patterns are quite similar despite the modification with DND, although there is a little shift in the (100) and (002) peaks. Interestingly, there is no DND peak in the pattern of g- $\mathrm{C}_{3} \mathrm{~N}_{4}-$ DND (Fig. $1 \mathrm{~b}$ ), suggesting that when the DND content is very low, it might be undetected by XRD. However, as the DND content increases, the characteristic diamond peak appears at around $43.6^{\circ}$, ascribed to the interlayer spacing of the (111) diffraction plane in diamond, ${ }^{20}$ as shown in Fig. 1c. The slight shift in the peaks can be attributed to the doping with DND in $\mathrm{g}^{-} \mathrm{C}_{3} \mathrm{~N}_{4}$, and it was observed that upon increasing DND content, the shift in peaks becomes larger. We hypothesized that DND doping can affect the lattice parameters, resulting in a small shift in the peak

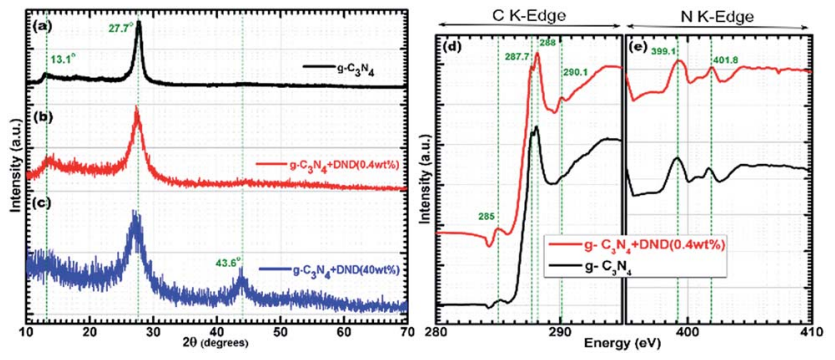

Fig. 1 XRD patterns of (a) $\mathrm{g}-\mathrm{C}_{3} \mathrm{~N}_{4}$, (b) $\mathrm{g}-\mathrm{C}_{3} \mathrm{~N}_{4}-\mathrm{DND}(0.4 \mathrm{wt} \%$ ), and (c) $\mathrm{g}-\mathrm{C}_{3} \mathrm{~N}_{4}-\mathrm{DND}$ (40 wt\%). XANES (d) $\mathrm{C} 1 \mathrm{~s}$ spectra and (e) $\mathrm{N}$ 1s spectra of $\mathrm{g}-\mathrm{C}_{3} \mathrm{~N}_{4}$ and $\mathrm{g}-\mathrm{C}_{3} \mathrm{~N}_{4}-\mathrm{DND}(0.4 \mathrm{wt} \%$ ). position. ${ }^{21}$ Thus, a small amount of DND does not affect the lattice structure, which is very beneficial for the photocatalytic properties of the hybrid. X-ray absorption near edge structure (XANES) analysis was conducted to further verify the structure of our samples. In the XANES C 1s spectra (see Fig. 1d), both g$\mathrm{C}_{3} \mathrm{~N}_{4}$ and $\mathrm{g}^{-} \mathrm{C}_{3} \mathrm{~N}_{4}-\mathrm{DND}(0.4 \mathrm{wt} \%)$ show characteristic resonances at around $285 \mathrm{eV}, 287.7 \mathrm{eV}$, and $288 \mathrm{eV}$, but the spectrum of $\mathrm{g}-\mathrm{C}_{3} \mathrm{~N}_{4}-\mathrm{DND}(0.4 \mathrm{wt} \%)$ has an additional peak at around $290.1 \mathrm{eV}$, which can be ascribed to $\mathrm{sp}^{3}$ carbon. The peak at $285 \mathrm{eV}\left(1 \mathrm{~s}-\pi^{*} \mathrm{C}=\mathrm{C}\right)$ is ascribed to a typical transition of graphite, ${ }^{22}$ which confirms the presence of graphitic carbon in both samples. Another peak at $287.7 \mathrm{eV}\left(1 \mathrm{~s}-\pi^{*} \mathrm{C}-\mathrm{N}\right)$ is attributed to the characteristic resonance of a carbon atom bonded with three nitrogen atoms in $s$-triazine, whereas the peak at $288 \mathrm{eV}$ $\left(1 \mathrm{~s}-\pi^{*} \mathrm{C}-\mathrm{N}-\mathrm{C}\right)$ is attributed to the characteristic resonance of a nitrogen atom bonded with two carbon atoms in $s$-triazine. ${ }^{23}$ We attributed the resonance at around $290.1 \mathrm{eV}\left(1 \mathrm{~s}-\sigma^{*} \mathrm{C} \equiv \mathrm{C}\right)$ to DND. ${ }^{24}$ In the XRD pattern, we were unable to detect DND at low concentrations, but as the XANES technique is more sensitive to electronic structures, we were able to detect even small concentrations of DND. Furthermore, the XANES N 1s spectra of both samples are quite similar, as shown in Fig. 1e. Both have typical $\pi^{*}$ resonances at $399.1 \mathrm{eV}$ and $401.8 \mathrm{eV}$, and these resonances can be ascribed to the $\mathrm{C}-\mathrm{N}-\mathrm{C}$ coordination in one tri-s-triazine unit and $\mathrm{N}-3 \mathrm{C}$ bridging between three tri-s-triazine moieties, respectively. ${ }^{23}$ The chemical structures of pristine g$\mathrm{C}_{3} \mathrm{~N}_{4}$ and the $\mathrm{g}-\mathrm{C}_{3} \mathrm{~N}_{4}-\mathrm{DND}$ hybrid were determined by FTIR spectroscopy, as shown in Fig. S2. $\dagger$ The sharp band at around $810 \mathrm{~cm}^{-1}$ can be attributed to the tri-s-triazine subunits. ${ }^{25}$ The band at $1315 \mathrm{~cm}^{-1}$ can be assigned to the stretching vibrations of the $\mathrm{C}-\mathrm{N}-\mathrm{C}$ bonds. ${ }^{26}$ Several broad peaks between 1200 and $1600 \mathrm{~cm}^{-1}$ are ascribed to the vibrations of aromatic $\mathrm{C}-\mathrm{N}$ heterocycles. ${ }^{25,26}$ The bands at 2850 and $2919 \mathrm{~cm}^{-1}$ can be assigned to the $\mathrm{C}-\mathrm{H}$ and $\mathrm{N}-\mathrm{H}$ stretching modes. ${ }^{27}$ The bands between 3000 and $3500 \mathrm{~cm}^{-1}$ can be assigned to primary and secondary amines, ${ }^{28}$ incomplete graphitic condensation, ${ }^{29}$ hydrogen bond adsorption ${ }^{27,30}$ and surface-adsorbed water molecules. ${ }^{29}$ The surface morphology and structure of $\mathrm{g}-\mathrm{C}_{3} \mathrm{~N}_{4}$ and $\mathrm{g}-\mathrm{C}_{3} \mathrm{~N}_{4}-\mathrm{DND}$ hybrid was further examined by transmission electron microscopy (TEM), as shown in Fig. 2. It was observed that $\mathrm{g}-\mathrm{C}_{3} \mathrm{~N}_{4}$ has a layered structure because of the graphitic planes constituted by tri-s-triazine ${ }^{19}$ units, as shown in Fig. $2 \mathrm{a}$. The thickness of the g- $\mathrm{C}_{3} \mathrm{~N}_{4}$ layers in the g- $\mathrm{C}_{3} \mathrm{~N}_{4}$-DND hybrid $(0.4 \mathrm{wt} \%)$ is very low and contains pores of a size of tens of nanometres ${ }^{31}$ (see Fig. $2 \mathrm{~b}$ and $\mathrm{S} 3 \dagger$ ). It can also be seen that the edges of the $\mathrm{g}-\mathrm{C}_{3} \mathrm{~N}_{4}$ layers are back-folded. Finally, it was observed that when preparing the hybrid, the DND can be deposited easily on the surface and within the layers of $\mathrm{g}-\mathrm{C}_{3} \mathrm{~N}_{4}$ (see Fig. S4†).

At high concentrations, DND covered the $\mathrm{g}-\mathrm{C}_{3} \mathrm{~N}_{4}$ layer, as seen in Fig. $2 \mathrm{c}$ and $\mathrm{S} 5, \dagger$ which may block the light from reaching the $\mathrm{g}-\mathrm{C}_{3} \mathrm{~N}_{4}$ surface. It was also observed that the colour of the sample changed from light yellow to blackish yellow in the g$\mathrm{C}_{3} \mathrm{~N}_{4}+$ DND (40 wt\%) hybrid (see Fig. S6 $\dagger$ ). Moreover, in the small scale image of g- $\mathrm{C}_{3} \mathrm{~N}_{4}$-DND (0.4 wt\%), shown in Fig. $2 \mathrm{~d}$, DND clusters can be seen along with the layered structure of $\mathrm{g}$ $\mathrm{C}_{3} \mathrm{~N}_{4}$ having pores of nanometre size. The HRTEM image 

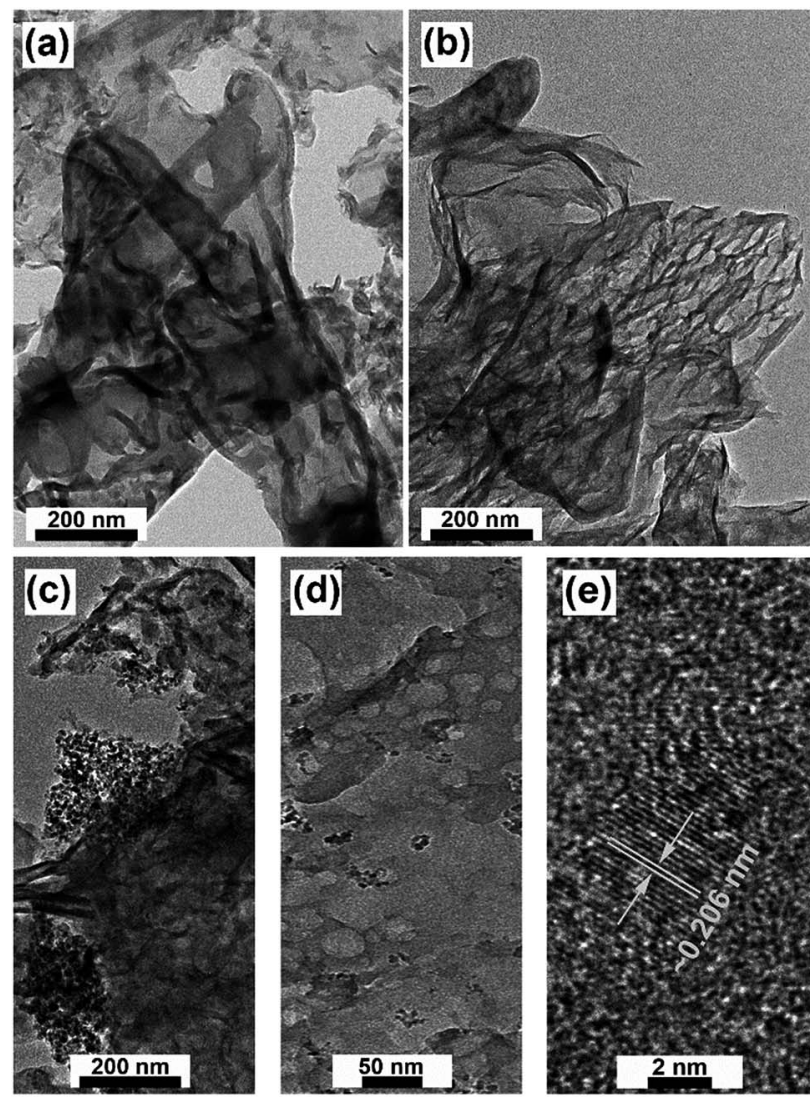

Fig. 2 TEM images of (a) $\mathrm{g}-\mathrm{C}_{3} \mathrm{~N}_{4}$, (b) large scale $\mathrm{g}-\mathrm{C}_{3} \mathrm{~N}_{4}-\mathrm{DND}(0.4$ $w t \%),(c) g-C_{3} N_{4}-D N D(40 w t \%),(d)$ small scale $g-C_{3} N_{4}-D N D(0.4$ $w t \%)$, and (e) HRTEM image of $\mathrm{g}-\mathrm{C}_{3} \mathrm{~N}_{4}-\mathrm{DND}(0.4 \mathrm{wt} \%$ ).

revealed the lattice fringes of DND, with an interplanar spacing of approximately $0.206 \mathrm{~nm}$, as shown in Fig. 2e, which is in agreement with the XRD results (Fig. 1c) and confirm the presence of DND on the $\mathrm{g}-\mathrm{C}_{3} \mathrm{~N}_{4}$ layer. ${ }^{32}$ Atomic force microscopy (AFM) measurements confirm the ultralow thickness of the $\mathrm{g}$ $\mathrm{C}_{3} \mathrm{~N}_{4}$ layer, of around $2-6 \mathrm{~nm}$ as shown in Fig. $\mathrm{S} 7, \dagger$ which is in agreement with the TEM image (Fig. 2a). It was observed that the addition of DND can increase the thickness of the sample. Thus, a small content of DND increases the thickness of the layer by $2-3 \mathrm{~nm}$ (see Fig. S7 $\dagger$ ). A high content of DND can increase thickness substantially compared with $\mathrm{g}-\mathrm{C}_{3} \mathrm{~N}_{4}$. The thickness of the hybrid with $10 \mathrm{wt} \%$ DND is around 17-20 nm. Because of their small size and high surface area, DND particles tend to agglomerate, and at high concentrations, the agglomeration is prominent. Therefore, we can conclude that the large thickness of the hybrid sample at high concentrations is due to DND agglomeration. As high concentrations lead to a large sample thickness, we can predict that samples with a high concentration of DND do not have a high photocatalytic activity. However, at low concentrations, the change in thickness is not so prominent, and hence this sample can be suitable for photocatalysis. The composition of our samples was investigated by X-ray photoelectron spectroscopy (XPS). XPS survey scans clearly indicated that the composition of $\mathrm{g}-\mathrm{C}_{3} \mathrm{~N}_{4}$ is carbon and nitrogen, as shown in Fig. S3. $\uparrow$ No distinctive oxygen peak was observed. It was suggested that the release of oxygen containing gases at high temperatures causes the removal of oxygen from the final products. ${ }^{33}$ The carbon peak is present at around $287.7 \mathrm{eV}$, while the nitrogen peak is present at around $398 \mathrm{eV}$ (see Fig. S8†).

The deconvoluted $\mathrm{C} 1 \mathrm{~s}$ spectrum of $\mathrm{g}-\mathrm{C}_{3} \mathrm{~N}_{4}$ has three peaks at around $288 \mathrm{eV}, 286.8 \mathrm{eV}$, and $284.8 \mathrm{eV}$ (see Fig. 3a), whereas the deconvoluted $\mathrm{C} 1 \mathrm{~s}$ spectrum of g- $\mathrm{C}_{3} \mathrm{~N}_{4}-\mathrm{DND}$ (0.4 wt $\%$ ) displays peaks at around $287.5 \mathrm{eV}, 286.6 \mathrm{eV}$, and $284.1 \mathrm{eV}$ (see Fig. 3b). The peaks at around $288 \mathrm{eV}$ and $287.5 \mathrm{eV}$ can be assigned to $\mathrm{sp}^{2}$ carbon. ${ }^{33}$ The characteristic graphite carbon peak of $\mathrm{g}-\mathrm{C}_{3} \mathrm{~N}_{4}$ is located at around 284.8 and $284.1 \mathrm{eV}$. However, the peak for $\mathrm{sp}^{2}$ carbon bonded to carbon overlaps with the peak for $\mathrm{sp}^{2}$ carbon bonded to nitrogen, and therefore it is difficult to assign them to a specific bond. However, $\mathrm{sp}^{2}$ carbon bonded to nitrogen is only observed for a high concentration of nitrogen. ${ }^{34}$ Therefore, we concluded that in $\mathrm{g}-\mathrm{C}_{3} \mathrm{~N}_{4}$, this peak might be ascribed to $\mathrm{sp}^{2}$ carbon bonded to nitrogen, whereas upon addition of DND, carbon content increases and the peak can be attributed to $\mathrm{sp}^{2}$ carbon bonded to carbon, as it is more prominent in $\mathrm{g}-\mathrm{C}_{3} \mathrm{~N}_{4}-$ DND $(0.4 \mathrm{wt} \%)$. The deconvoluted $\mathrm{N}$ 1s spectrum of $\mathrm{g}-\mathrm{C}_{3} \mathrm{~N}_{4}$ shows two peaks at around $398.1 \mathrm{eV}$ and $399.3 \mathrm{eV}$ (Fig. 3c), whereas the deconvoluted $\mathrm{N}$ 1s spectrum of $\mathrm{g}-\mathrm{C}_{3} \mathrm{~N}_{4}-\mathrm{DND}(0.4$ $\mathrm{wt} \%$ ) displays peaks at around $397.8 \mathrm{eV}$ and $400.0 \mathrm{eV}$ (Fig. 3d). The peaks at around $398.1 \mathrm{eV}$ and $397.8 \mathrm{eV}$ can be assigned to $\mathrm{sp}^{2}$ hybridized aromatic $\mathrm{N}$ bonded to carbon atoms. ${ }^{33}$ The peaks at around $399.3 \mathrm{eV}$ and $400.0 \mathrm{eV}$ can be assigned to quaternary $\mathrm{N}$ bonded to three carbon atoms in the aromatic cycles. ${ }^{33}$ Therefore, we can conclude that there is no significant change in the structure, morphology, composition and chemical state of $\mathrm{g}-\mathrm{C}_{3} \mathrm{~N}_{4}$ after the addition of DND, and the hybrid is identical to the reference $\mathrm{g}-\mathrm{C}_{3} \mathrm{~N}_{4}$. From the TEM image (Fig. 2d), it can be observed that the hybrid sample has a porous structure with
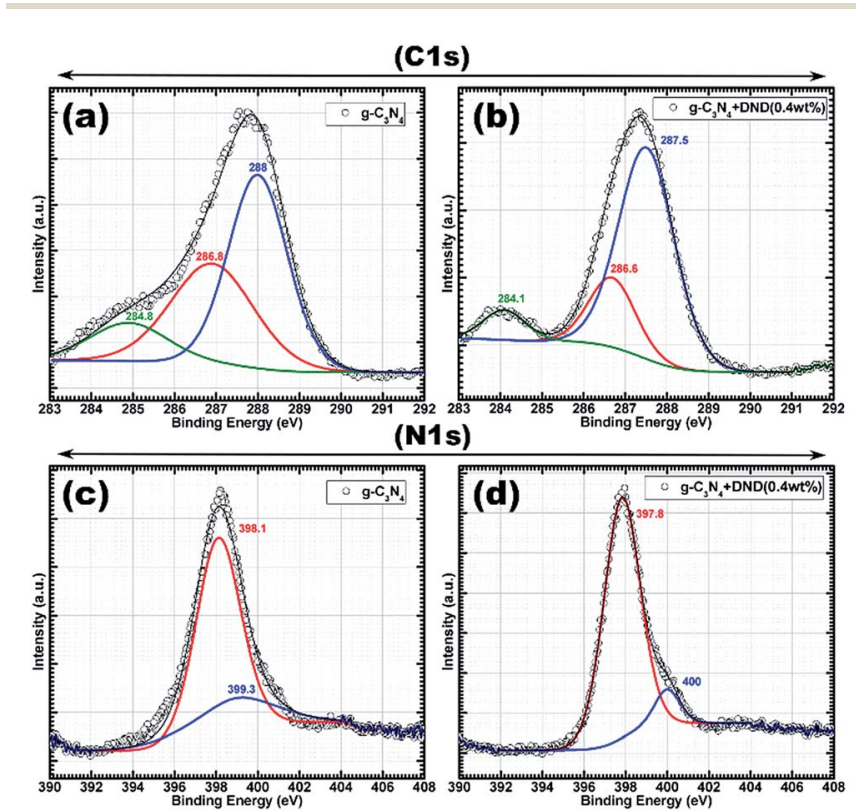

Fig. 3 XPS C 1s spectra of (a) $\mathrm{g}-\mathrm{C}_{3} \mathrm{~N}_{4}$ and (b) g- $\mathrm{C}_{3} \mathrm{~N}_{4}-\mathrm{DND}(0.4 \mathrm{wt} \%$ ); $\mathrm{N}$ 1s spectra of (c) g- $\mathrm{C}_{3} \mathrm{~N}_{4}$ and (d) $\mathrm{g}-\mathrm{C}_{3} \mathrm{~N}_{4}-\mathrm{DND}$ (0.4 wt\%). 
pores of tens of nanometres. The specific surface area, total pore volume and pore diameter were investigated by the Brunauer-Emmett-Teller (BET) method, and the data obtained are given in Table 1 for $\mathrm{g}-\mathrm{C}_{3} \mathrm{~N}_{4}$ and the $\mathrm{g}-\mathrm{C}_{3} \mathrm{~N}_{4}-\mathrm{DND}$ hybrids. The $\mathrm{N}_{2}$ adsorption-desorption isotherms are shown in Fig. S9. $\uparrow$ The specific surface area of $\mathrm{g}-\mathrm{C}_{3} \mathrm{~N}_{4}-\mathrm{DND}(0.4 \mathrm{wt} \%)$ was found to be $73.4 \mathrm{~m}^{2} \mathrm{~g}^{-1}$, whereas the specific surface area of $\mathrm{g}-\mathrm{C}_{3} \mathrm{~N}_{4}$ was 35.3 $\mathrm{m}^{2} \mathrm{~g}^{-1}$. Although the shape of the isotherms is identical, the hybrid material showed a two-fold enhancement in the specific surface area. The specific surface areas of $\mathrm{g}-\mathrm{C}_{3} \mathrm{~N}_{4}-\mathrm{DND}(10 \mathrm{wt} \%)$ and $\mathrm{g}-\mathrm{C}_{3} \mathrm{~N}_{4}-\mathrm{DND}\left(40 \mathrm{wt} \%\right.$ ) were found to be around $45.26 \mathrm{~m}^{2}$ $\mathrm{g}^{-1}$ and $43.87 \mathrm{~m}^{2} \mathrm{~g}^{-1}$, which is higher than that of $\mathrm{g}-\mathrm{C}_{3} \mathrm{~N}_{4}$ but smaller than that of $\mathrm{g}-\mathrm{C}_{3} \mathrm{~N}_{4}-\mathrm{DND}(0.4 \mathrm{wt} \%)$. Due to a high content of DND, the smaller area could be a result of DND agglomeration. However, at very low DND content, the specific surface area was around $42.27 \mathrm{~m}^{2} \mathrm{~g}^{-1}$, which is only slightly higher than that of reference $\mathrm{g}-\mathrm{C}_{3} \mathrm{~N}_{4}$. The total pore volume for pores with a diameter of less than $83.68 \mathrm{~nm}$ at $P / P_{\mathrm{o}}=0.976464$ was found to be $0.097 \mathrm{~cm}^{3} \mathrm{~g}^{-1}$ for $\mathrm{g}-\mathrm{C}_{3} \mathrm{~N}_{4}$. Similarly, the total pore volume for pores with a diameter of less than $84.96 \mathrm{~nm}$ at $P / P_{\mathrm{o}}=0.976828$ was found to be $0.322 \mathrm{~cm}^{3} \mathrm{~g}^{-1}$ for $\mathrm{g}-\mathrm{C}_{3} \mathrm{~N}_{4}+\mathrm{DND}$ $(0.4 \mathrm{wt} \%)$, which is approximately three times that for $\mathrm{g}-\mathrm{C}_{3} \mathrm{~N}_{4}$.

Furthermore, the samples with a high content of DND showed intermediate pore volumes, whereas the sample with a very low content showed a pore volume closer to the reference $\mathrm{g}^{-} \mathrm{C}_{3} \mathrm{~N}_{4}$ sample. In the samples with a high DND content, DND surrounds the $\mathrm{g}-\mathrm{C}_{3} \mathrm{~N}_{4}$ layer (as seen in Fig. S5 $\dagger$ ), ultimately leading to a decrease of the pore volume. A comparison of the pore size distribution curves is shown in Fig. S10. $\uparrow$ The mean pore diameter for hybrids is higher, which can be attributed to the DND clusters. It can be seen that $\mathrm{g}-\mathrm{C}_{3} \mathrm{~N}_{4}-\mathrm{DND}(0.4 \mathrm{wt} \%)$ exhibits the largest pore volume, which agrees with the TEM results. The mesoporous structure indicates a high surface area and, ultimately, more active sites for charge transfer. Subsequently, the photocatalytic activity of the hybrids was studied by UV-Vis diffuse reflectance (UV-Vis-DRS) and photoluminescence (PL) spectroscopy. According to the UV-Vis-DRS spectra, shown in Fig. 4a, both $\mathrm{g}-\mathrm{C}_{3} \mathrm{~N}_{4}$ and $\mathrm{g}-\mathrm{C}_{3} \mathrm{~N}_{4}-\mathrm{DND}(0.4 \mathrm{wt} \%)$ exhibit semiconductor-like optical characteristics. The optical absorption is red-shifted, probably because of the different polymerization path caused by the addition of DND, which may result in a change in the electronic state of the hybrid ${ }^{35}$ with respect to the reference $\mathrm{g}-\mathrm{C}_{3} \mathrm{~N}_{4}$. The typical absorption edge for $\mathrm{g}-\mathrm{C}_{3} \mathrm{~N}_{4}$ is observed at $458 \mathrm{~nm}$ whereas g- $\mathrm{C}_{3} \mathrm{~N}_{4}-\mathrm{DND}$ (0.4 wt\%) shows an absorption edge at around $496 \mathrm{~nm}$ (Fig. 4a). The absorption spectrum was further analysed by plotting $h \nu v s$. $(A h \nu)^{1 / 2}$ for

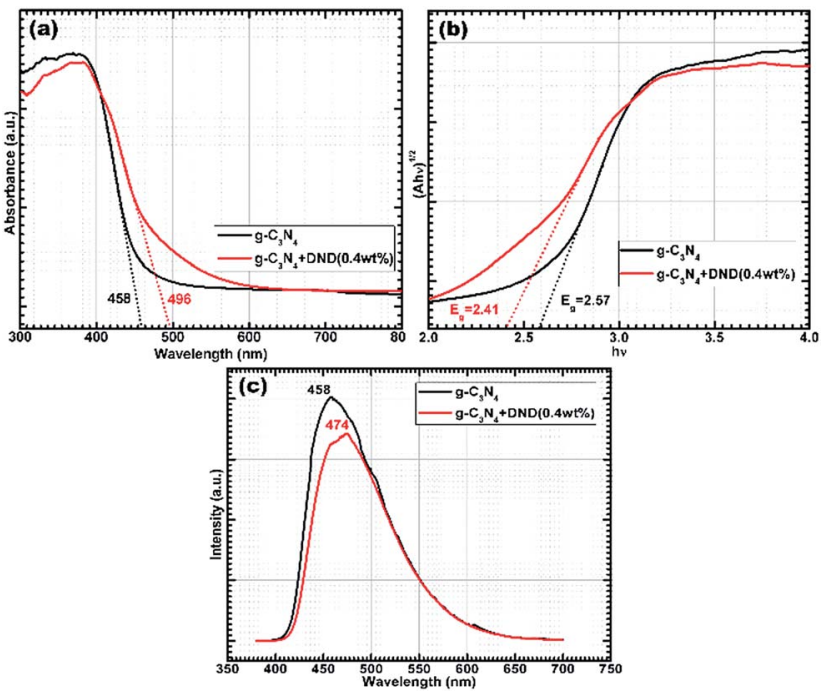

Fig. 4 (a) UV-Vis-DRS; (b) plot of $h \nu$ vs. $(A h \nu)^{1 / 2}$ for indirect band gap energy calculations and (c) steady-state PL spectra.

indirect transition, as shown in Fig. $4 \mathrm{~b}$. The estimated band gap of $\mathrm{g}-\mathrm{C}_{3} \mathrm{~N}_{4}$ is $2.57 \mathrm{eV}$, while the estimation for the band gap of $\mathrm{g}$ $\mathrm{C}_{3} \mathrm{~N}_{4}$-DND (0.4 wt\%) is approximately $2.41 \mathrm{eV}$ (Fig. 4b). The band gap energies for direct transition, as estimated by plotting $h \nu$ vs. $(A h \nu)^{2}$, were found to be approximately $2.79 \mathrm{eV}$ for $\mathrm{g}-\mathrm{C}_{3} \mathrm{~N}_{4}$ and $2.62 \mathrm{eV}$ for $\mathrm{g}-\mathrm{C}_{3} \mathrm{~N}_{4}-\mathrm{DND}(0.4 \mathrm{wt} \%)$, as shown in Fig. S11. $\dagger$ The decrease in the band gap energy for the hybrid shows a shift towards the visible region, which indicates that the hybrid material is more active in the visible region as compared with $\mathrm{g}$ $\mathrm{C}_{3} \mathrm{~N}_{4}$. The photogenerated charge carrier separation ability of $\mathrm{g}$ $\mathrm{C}_{3} \mathrm{~N}_{4}$ and $\mathrm{g}-\mathrm{C}_{3} \mathrm{~N}_{4}-\mathrm{DND}(0.4 \mathrm{wt} \%)$ was investigated by steadystate photoluminescence (PL) spectroscopy, as shown in Fig. 4c. The band shift clearly indicates that $\mathrm{g}-\mathrm{C}_{3} \mathrm{~N}_{4}-\mathrm{DND}(0.4$ $\mathrm{wt} \%$ ) is more active in the visible region of the spectrum (Fig. 4c). It was observed that the PL spectrum of $g-\mathrm{C}_{3} \mathrm{~N}_{4}$ displays a band at around $458 \mathrm{~nm}$, whereas in the spectrum of $\mathrm{g}-\mathrm{C}_{3} \mathrm{~N}_{4}-$ DND $(0.4 \mathrm{wt} \%)$ this band is shifted to $474 \mathrm{~nm}$. In addition to the red shift in the emission spectrum of $\mathrm{g}-\mathrm{C}_{3} \mathrm{~N}_{4}-\mathrm{DND}(0.4 \mathrm{wt} \%)$, the PL intensity was also lower as compared with $\mathrm{g}-\mathrm{C}_{3} \mathrm{~N}_{4}$. This indicates that $\mathrm{g}-\mathrm{C}_{3} \mathrm{~N}_{4}-\mathrm{DND}(0.4 \mathrm{wt} \%)$ has a better ability to separate the photogenerated charge carriers under visible-light illumination. Furthermore, a broad emission band was observed in the $\sim 420-620 \mathrm{~nm}$ range for both samples, which could be attributed to band-gap emission. ${ }^{36}$ The PL results suggest that in the $\mathrm{g}-\mathrm{C}_{3} \mathrm{~N}_{4}-\mathrm{DND}(0.4 \mathrm{wt} \%)$ hybrid, most of the

Table 1 BET data: specific surface area, total pore volume, and mean pore diameter for $\mathrm{g}-\mathrm{C}_{3} \mathrm{~N}_{4}$ and g- $\mathrm{C}_{3} \mathrm{~N}_{4}+\mathrm{DND}$ hybrids

\begin{tabular}{llll}
\hline Sample & $\begin{array}{l}\text { Specific surface } \\
\text { area }\left(\mathrm{m}^{2} \mathrm{~g}^{-1}\right)\end{array}$ & $\begin{array}{l}\text { Total pore volume } \\
\left(\mathrm{cm}^{3} \mathrm{~g}^{-1}\right)\end{array}$ & $\begin{array}{l}\text { Mean pore diameter } \\
(\mathrm{N} \mathrm{m})\end{array}$ \\
\hline $\mathrm{g}-\mathrm{C}_{3} \mathrm{~N}_{4}+$ DND $(0.4 \mathrm{wt} \%)$ & 73.4 & 0.322 & 17.55 \\
$\mathrm{~g}-\mathrm{C}_{3} \mathrm{~N}_{4}+$ DND $(0.2 \mathrm{wt} \%)$ & 42.27 & 0.120 & 11.37 \\
$\mathrm{~g}-\mathrm{C}_{3} \mathrm{~N}_{4}+$ DND $(10 \mathrm{wt} \%)$ & 45.26 & 0.199 & 17.26 \\
g- $\mathrm{C}_{3} \mathrm{~N}_{4}+$ DND $(20 \mathrm{wt} \%)$ & 43.87 & 0.196 & 17.56 \\
g- $\mathrm{C}_{3} \mathrm{~N}_{4}$ & 35.3 & 0.097 & 11.04
\end{tabular}


photoexcited charge carriers de-excite through non-radiative channels, whereas for $\mathrm{g}-\mathrm{C}_{3} \mathrm{~N}_{4}$, most of the photoexcited charge carriers decay through emission. ${ }^{37}$ Hence, we can conclude that the hybrid exhibits a higher photocatalytic activity than $\mathrm{g}_{-} \mathrm{C}_{3} \mathrm{~N}_{4}$. Subsequently, we conducted photocatalysis experiments using hybrids with different concentrations of DND. Fig. 5a shows a comparison of the photocatalytic activity of $\mathrm{g}-\mathrm{C}_{3} \mathrm{~N}_{4}$ and $\mathrm{g}-\mathrm{C}_{3} \mathrm{~N}_{4}-\mathrm{DND}$ hybrids with different concentrations of DND. It was found that at higher concentrations of DND the hybrids do not show an enhanced photocatalytic activity, whereas the hybrid with a low amount of DND shows a high catalytic activity as compared with g- $\mathrm{C}_{3} \mathrm{~N}_{4}$. It was suggested that high concentrations of DND block the visible light to reach the g- $\mathrm{C}_{3} \mathrm{~N}_{4}$ surface, rendering it inactive for photocatalysis. Samples with different concentrations of DND were tested and it was found that if the DND content was lower than $1.5 \mathrm{wt} \%$ but higher than $0.2 \mathrm{wt} \%$, the material exhibits a high catalytic activity compared with $\mathrm{g}-\mathrm{C}_{3} \mathrm{~N}_{4}$ (see Fig. 5a). The maximum catalytic activity is obtained with the $\mathrm{g}-\mathrm{C}_{3} \mathrm{~N}_{4}-\mathrm{DND}$ (0.4 wt\%) sample, as shown in Fig. 5b. It was also found that more than $2000 \mu$ moles of hydrogen were produced in $48 \mathrm{~h}$ using g- $\mathrm{C}_{3} \mathrm{~N}_{4}-\mathrm{DND}(0.4 \mathrm{wt} \%)$ hybrid (see Fig. $5 \mathrm{~b}$ ), which is $50 \%$ higher than the amount of hydrogen produced by $\mathrm{g}-\mathrm{C}_{3} \mathrm{~N}_{4}$. In this study, the maximum quantum yield observed for $\mathrm{g}_{-} \mathrm{C}_{3} \mathrm{~N}_{4}-$ DND $(0.4 \mathrm{wt} \%)$ is approximately $6.25 \%$, whereas the quantum yield for g- $\mathrm{C}_{3} \mathrm{~N}_{4}$ is roughly $4.97 \%$ (see ESI $\dagger$ ). In order to evaluate the stability of the samples, photocatalysis experiments were repeated after a gap of 10 days and 30 days, and conducted for 24 hours (see Fig. $5 c$ ). It was found that $\mathrm{g}-\mathrm{C}_{3} \mathrm{~N}_{4}-\mathrm{DND}(0.4 \mathrm{wt} \%)$ shows a consistent production of hydrogen despite being kept without light for 10 and 30 days, which indicates that the photocatalyst is stable under the experimental conditions. Stability tests conducted through repeated photocatalysed
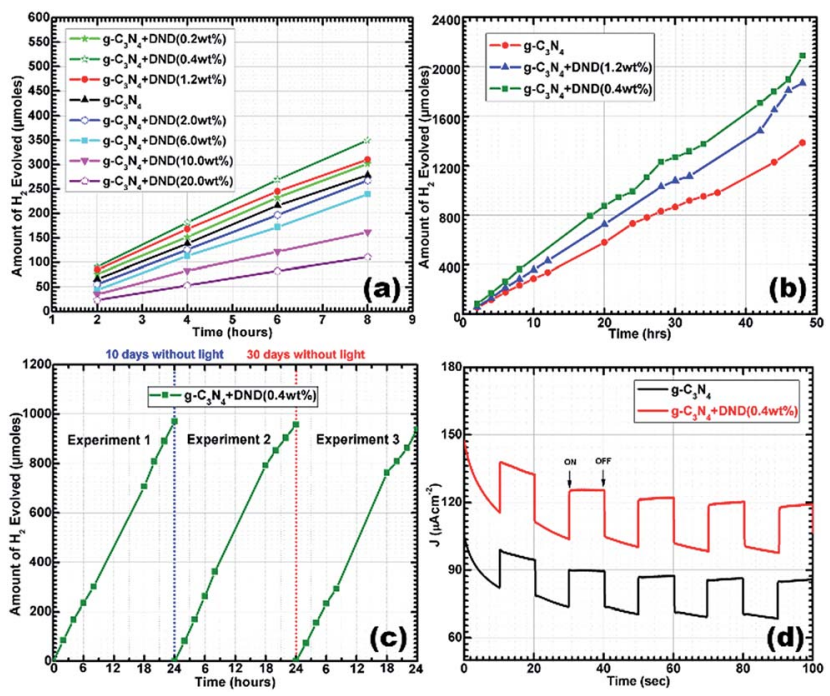

Fig. 5 (a) Comparison of the HER with $\mathrm{g}-\mathrm{C}_{3} \mathrm{~N}_{4}-\mathrm{DND}$ hybrids having different concentrations of DND; (b) time course of hydrogen production for g- $\mathrm{C}_{3} \mathrm{~N}_{4}, \mathrm{~g}-\mathrm{C}_{3} \mathrm{~N}_{4}-\mathrm{DND}(0.4 \mathrm{wt} \%)$ and g- $\mathrm{C}_{3} \mathrm{~N}_{4}-\mathrm{DND}(1.2$ wt\%); (c) stability testing of $\mathrm{g}-\mathrm{C}_{3} \mathrm{~N}_{4}-\mathrm{DND}(0.4 \mathrm{wt} \%$ ) for the HER; (d) photocurrents recorded for $\mathrm{g}-\mathrm{C}_{3} \mathrm{~N}_{4}$ and $\mathrm{g}-\mathrm{C}_{3} \mathrm{~N}_{4}-\mathrm{DND}(0.4 \mathrm{wt} \%$ ). reactions showed only a $3.5 \%$ (see Fig. $5 \mathrm{c}$ ) decrease in the photocatalytic activity over a period of 40 days.

It is important to mention that in the absence of light, no catalytic activity was observed. The photocurrent response was measured to further confirm the photoactivity of the samples, as shown in Fig. 5d. It can be clearly seen that there was current when the lamp was on, and there was no current when the lamp was off. Details of the proposed photocatalytic reaction mechanism are presented in the ESI. $\dagger$ In a typical photocatalytic reaction, photons are absorbed by the catalyst, which generates electrons and holes. Generally, charge carriers tend to recombine rapidly and only a small number of charges take part in the photocatalytic reaction. This high recombination rate decreased after the addition of DND, leading to charge separation and prolonging the charge carrier lifetime. Moreover, the electrons further participate in hydrogen reduction reactions at the surface sites, while the holes take part in oxidation processes (see ESI $\dagger$ ). The rapid transfer of these charges from the inner layers to the surface active sites is important during the HER. ${ }^{38}$ We proposed that DND plays an active role in the rapid transfer of charges to help them reach the active sites in less time, ultimately increasing charge separation (Fig. 4c). DND has a very large specific surface area, and also has defect sites and surface functional groups which could help to transfer the charge carriers produced by the catalyst during photon absorption. Time resolved fluorescence decay experiments (Fig. 6a) were conducted to understand the photophysical phenomenon. It was observed that both $\mathrm{g}^{-} \mathrm{C}_{3} \mathrm{~N}_{4}$ and the hybrid exhibit exponentially decaying intensities, as shown in Fig. 6 a. In comparison with $\mathrm{g}-\mathrm{C}_{3} \mathrm{~N}_{4}$, the hybrid shows slightly slower decay kinetics. After fitting the decay spectra, three different radiative lifetimes with relative percentages were obtained, given in Table 2.

In summary, the highest and medium lifetimes of the hybrid sample increase with respect to those of $\mathrm{g}-\mathrm{C}_{3} \mathrm{~N}_{4}$. We can observe that there is an increase in lifetime for almost $65 \%$ of charge carriers in the hybrid sample. There is no noticeable change for almost $35 \%$ of charge carriers, with the shortest lifetime. The average charge carrier lifetime also increased from 8.53 in $\mathrm{g}$ $\mathrm{C}_{3} \mathrm{~N}_{4}$ to $10.63 \mathrm{~ns}$ in the hybrid. Thus, we concluded that the radiative lifetime of $65 \%$ of charge carriers increased because of the addition of a small amount of DND $(0.4 \mathrm{wt} \%)$. The increased lifetime of the photoexcited charge carriers indicates their involvement in photocatalytic reactions before recombination. ${ }^{39}$
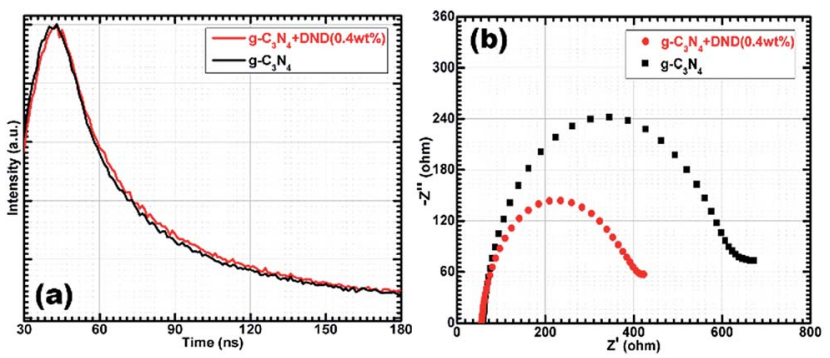

Fig. 6 (a) Time resolved fluorescence decay (b) EIS Nyquist plots of g$\mathrm{C}_{3} \mathrm{~N}_{4}$ and $\mathrm{g}-\mathrm{C}_{3} \mathrm{~N}_{4}+$ DND (0.4 wt\%). 
Table 2 Radiative fluorescence lifetimes along with their relative percentages of photoexcited charge carriers after fitting the decay spectra of g$\mathrm{C}_{3} \mathrm{~N}_{4}-$ DND (0.4 wt\%) and g- $\mathrm{C}_{3} \mathrm{~N}_{4}$

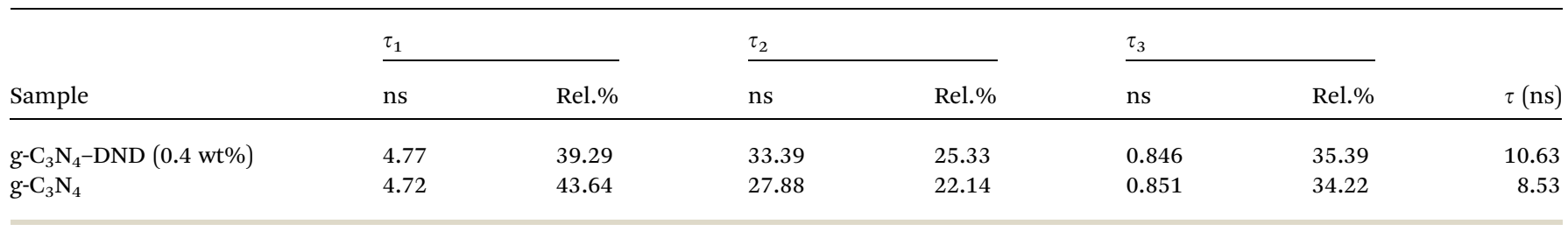

The intensity decrease in the PL spectra (steady-state fluorescence) also supports that some photoexcited charge carriers exhibit non-radiative activity (Fig. 4c). It has been suggested in the literature ${ }^{39}$ that an increased lifetime led to an improved electron transfer and/or changes in the electronic band structure. Furthermore, the photocurrent (Fig. $5 \mathrm{~d}$ ) measured for $\mathrm{g}$ $\mathrm{C}_{3} \mathrm{~N}_{4}-\mathrm{DND}(0.4 \mathrm{wt} \%)$ was higher than the measured for g- $\mathrm{C}_{3} \mathrm{~N}_{4}$, which is in agreement with the optical absorption spectra of the samples and also suggests that the photocurrent is indeed induced by light. The electronic conductivity was examined by electrochemical impedance spectroscopy and measurements were recorded at an $\mathrm{AC}$ voltage of $1.5 \mathrm{~V}$ in the frequency range of $10^{5}$ to $10^{-2} \mathrm{~Hz}$. In Fig. $6 \mathrm{~b}$, the Nyquist plots show a smaller semicircle diameter for $\mathrm{g}_{-}-\mathrm{C}_{3} \mathrm{~N}_{4}-\mathrm{DND}(0.4 \mathrm{wt} \%)$. The Nyquist semicircle with a large diameter for $\mathrm{g}_{-} \mathrm{C}_{3} \mathrm{~N}_{4}$ indicates low conductivity with a poor electron transfer. On the other hand, the small diameter of the Nyquist semicircle for $\mathrm{g}-\mathrm{C}_{3} \mathrm{~N}_{4}-\mathrm{DND}$ (0.4 wt\%) indicates an improved electronic conductivity. Therefore, we can conclude that the charge transfer in the hybrid is more rapid than in $\mathrm{g}-\mathrm{C}_{3} \mathrm{~N}_{4}$. We had already tested the hybrid sample stability for the HER under experimental conditions, as shown in Fig. 5c. In addition, to confirm the structural stability of the hybrid sample, we analysed it by XRD after the photocatalysis experiment. The XRD pattern of the hybrid sample after the photocatalysis experiment, shown in Fig. S12, $\dagger$ is quite similar to the pattern shown in Fig. $1 \mathrm{~b}$. The XRD pattern of $\mathrm{g}-\mathrm{C}_{3} \mathrm{~N}_{4}-\mathrm{DND}(0.4 \mathrm{wt} \%)$ after the photocatalysis experiment displays peaks at $13.4^{\circ}$ and $27.3^{\circ}$, ascribed to the (100) and (002) planes, respectively. The structure of the hybrid sample after the photocatalysis experiment was further examined by TEM, as shown in Fig. S13. $\dagger$ It was found that the hybrid sample has a similar layered structure as the one shown in Fig. 2b. Therefore, we could conclude that no structural changes occurred and that the hybrid sample was highly stable during the photocatalysis experiment.

There can be several factors affecting the photocatalytic activity according to the above observations. First, the composition of the material is a key factor. Impurities can lead to low photocatalytic activity, and to eliminate them, we washed the samples after preparation with distilled water to remove any residual impurities. In addition, XRD, XANES and XPS analysis do not show any signs of residual impurities. Second, the dispersion and grain size of the sample also affects the photocatalytic activity. We used sonication to disintegrate the grains and also to disperse them uniformly. The sample grains were well-dispersed during the experiment by constant stirring. The thickness of the samples is crucial in photocatalysis, and TEM and AFM analyses confirm that the hybrid (0.4 wt\%) sample is composed of ultrathin layers. Thirdly, the electron transfer rate also improves the photocatalytic activity. We suggested that the presence of a sacrificial electron donor (methanol) and a cocatalyst $(\mathrm{Pt})$ would help to improve the electron transfer rate. Similar, findings were also obtained from UV-Vis-DRS and time resolved fluorescence decay analyses. Fourthly, the recombination of the charge carriers strongly affects the photocatalytic activity. The PL spectra confirms a lower recombination rate of charge carriers in $\mathrm{g}-\mathrm{C}_{3} \mathrm{~N}_{4}-\mathrm{DND}(0.4 \mathrm{wt} \%)$ than in pristine $\mathrm{g}$ $\mathrm{C}_{3} \mathrm{~N}_{4}$, which accounts for the high photocatalytic activity of g$\mathrm{C}_{3} \mathrm{~N}_{4}-\mathrm{DND}(0.4 \mathrm{wt} \%)$. Therefore, we concluded that DND plays an important role to decrease the recombination rate of charge carriers by improving the charge transfer to the photocatalytic active sites. However, at high concentrations, DND can aggregate on the ${ }^{-}-\mathrm{C}_{3} \mathrm{~N}_{4}$ layers and block the light absorption at the surface of $g-\mathrm{C}_{3} \mathrm{~N}_{4}$, which ultimately decreases the production of photoexcited charge carriers. Fifthly, the surface area has a crucial role in the photocatalytic activity. A large surface area indicates a higher number of photocatalytic active sites. The BET findings show that without any further changes in the synthetic procedure, the specific surface area can be increased two-fold and the total pore volume can be increased three-fold just by adding a small amount of DND. This increase in specific surface area can be attributed to the mesoporous structure of the hybrid. Finally, based on the steady-state PL and EIS Nyquist plots, we concluded that the decrease in the charge recombination rate as well as the improved charge transfer, are due to the higher number of active sites and the high surface area, which promote charge transfer, leading to a high photocatalytic activity for an efficient HER. It is worth mentioning that the stability and reusability of the photocatalyst are very important for practical applications. We observed that the hybrid sample (0.4 wt\%) shows a consistent hydrogen production in repeated photocatalysis experiments (see Fig. 5c). The XRD and TEM analyses of the samples after the photocatalysis experiment also prove that the hybrid samples are stable, and thus are reusable (see Fig. S12 and S13 $\dagger$ ). Therefore, the results demonstrate that the $\mathrm{g}-\mathrm{C}_{3} \mathrm{~N}_{4}+$ DND hybrid is an efficient, stable and reusable photocatalyst for the HER.

\section{Conclusions}

A highly efficient and stable hybrid photocatalyst was fabricated by the coupling of $\mathrm{g}-\mathrm{C}_{3} \mathrm{~N}_{4}$ layers with DND. Compared with g$\mathrm{C}_{3} \mathrm{~N}_{4}$, the hybrid material exhibited a much higher photocatalytic activity for the HER. A 50\% enhancement in the 
photocatalysed hydrogen production was observed for $\mathrm{g}-\mathrm{C}_{3} \mathrm{~N}_{4}-$ DND $(0.4 \mathrm{wt} \%)$ with respect to $\mathrm{g}-\mathrm{C}_{3} \mathrm{~N}_{4}$. Furthermore, it was also found that $\mathrm{g}-\mathrm{C}_{3} \mathrm{~N}_{4}-\mathrm{DND}(0.4 \mathrm{wt} \%)$ was stable under the experimental conditions and reusable. This work shows the great potential of $\mathrm{g}-\mathrm{C}_{3} \mathrm{~N}_{4}$ in solar energy conversion by coupling it with many other materials.

\section{Acknowledgements}

This study was financially supported by the National Basic Research Program of China (2014CB848900), the National Natural Science Foundation of China (U1532112, 11375198, 11574280), and the CUSF (WK2310000053). We are also thankful for the characterizations from NSRL light source (photoemission and MCD end-stations). Li Song thanks the recruitment program of global experts and the CAS Hundred Talent Program of China. Yasir A. Haleem acknowledges the CAS-TWAS president's fellowship for their financial support.

\section{References}

1 H. Gao, S. Yan, J. Wang and Z. Zou, Dalton Trans., 2014, 43, 8178-8183.

2 J. Liu, Y. Liu, N. Liu, Y. Han, X. Zhang, H. Huang, Y. Lifshitz, S.-T. Lee, J. Zhong and Z. Kang, Science, 2015, 347, 970-974.

3 X. Wang, K. Maeda, A. Thomas, K. Takanabe, G. Xin, J. M. Carlsson, K. Domen and M. Antonietti, Nat. Mater., 2009, 8, 76-80.

4 Y. Ishida, L. Chabanne, M. Antonietti and M. Shalom, Langmuir, 2014, 30, 447-451.

5 Y. Li, H. Zhang, P. Liu, D. Wang, Y. Li and H. Zhao, Small, 2013, 9, 3336-3344.

6 J. Duan, S. Chen, M. Jaroniec and S. Z. Qiao, ACS Nano, 2015, 9, 931-940.

7 M. Ni, M. K. H. Leung, D. Y. C. Leung and K. Sumathy, Renewable Sustainable Energy Rev., 2007, 11, 401-425.

8 D. Ghosh, G. Periyasamy and S. K. Pati, J. Phys. Chem. C, 2014, 118, 15487-15494.

9 D. Jiang, J. Zhu, M. Chen and J. Xie, J. Colloid Interface Sci., 2014, 417, 115-120.

10 J. Xu, L. Zhang, R. Shi and Y. Zhu, J. Mater. Chem. A, 2013, 1, 14766.

11 O. Shenderova, A. M. Panich, S. Moseenkov, S. C. Hens, V. Kuznetsov and H. M. Vieth, J. Phys. Chem. C, 2011, 115, 19005-19011.

12 P. Badziag, W. S. Verwoerd, W. P. Ellis and N. R. Greiner, Nature, 1990, 343, 244-245.

13 J.-Y. Raty and G. Galli, Nat. Mater., 2003, 2, 792-795.

14 S. Morimune, M. Kotera, T. Nishino, K. Goto and K. Hata, Macromolecules, 2011, 44, 4415-4421.

15 A. Krueger and D. Lang, Adv. Funct. Mater., 2012, 22, 890906.
16 A. Krueger, M. Ozawa, G. Jarre, Y. Liang, J. Stegk and L. Lu, Phys. Status Solidi A, 2007, 204, 2881-2887.

17 A. Krueger, J. Mater. Chem., 2008, 18, 1485.

18 Y. Tian, B. Chang, J. Lu, J. Fu, F. Xi and X. Dong, ACS Appl. Mater. Interfaces, 2013, 5, 7079-7085.

19 G. Liao, S. Chen, X. Quan, H. Yu and H. Zhao, J. Mater. Chem., 2012, 22, 2721.

20 Y. A. Haleem, P. Song, D. Liu, C. Wang, W. Gan, M. F. Saleem and L. Song, Materials, 2016, 9, 507.

21 J. Zhang, J. Sun, K. Maeda, K. Domen, P. Liu, M. Antonietti, X. Fu and X. Wang, Energy Environ. Sci., 2011, 4, 675.

22 I. P. Chang, K. C. Hwang, J. A. A. Ho, C. C. Lin, R. J. R. Hwu and J. C. Horng, Langmuir, 2010, 26, 3685-3689.

23 Y. Zheng, Y. Jiao, Y. Zhu, L. H. Li, Y. Han, Y. Chen, A. Du, M. Jaroniec and S. Z. Qiao, Nat. Commun., 2014, 5, 1-8.

24 Y. A. Haleem, D. Liu, W. Chen, C. Wang, C. Hong, Z. He, J. Liu, P. Song, S. Yu and L. Song, Composites, Part B, 2015, 78, 480-487.

25 J. Zhang, M. Zhang, L. Lin and X. Wang, Angew. Chem., Int. Ed., 2015, 54, 6297-6301.

26 S. Chu, Y. Wang, Y. Guo, J. Feng, C. Wang, W. Luo, X. Fan and Z. Zou, ACS Catal., 2013, 3, 912-919.

27 H. Sun, Y. Cao, L. Feng and Y. Chen, Sci. Rep., 2016, 6, 22808.

28 T. Y. Ma, Y. Tang, S. Dai and S. Z. Qiao, Small, 2014, 10, 23822389.

29 S. Martha, A. Nashim and K. M. Parida, J. Mater. Chem. A, 2013, 1, 7816.

30 D. Jiang, L. Chen, J. Xie and M. Chen, Dalton Trans., 2014, 43, 4878-4885.

31 X. She, H. Xu, Y. Xu, J. Yan, J. Xia, L. Xu, Y. Song, Y. Jiang, Q. Zhang and H. Li, J. Mater. Chem. A, 2014, 2, 2563.

32 G. N. Yushin, S. Osswald, V. I. Padalko, G. P. Bogatyreva and Y. Gogotsi, Diamond Relat. Mater., 2005, 14, 1721-1729.

33 J. Liu, T. Zhang, Z. Wang, G. Dawson and W. Chen, J. Mater. Chem., 2011, 21, 14398.

34 S. M. Lyth, Y. Nabae, S. Moriya, S. Kuroki, M. A. Kakimoto, J. I. Ozaki and S. Miyata, J. Phys. Chem. C, 2009, 113, 20148-20151.

35 M. Shalom, S. Gimenez, F. Schipper, I. Herraiz-Cardona, J. Bisquert and M. Antonietti, Angew. Chem., Int. Ed., 2014, 53, 3654-3658.

36 J. Xu, Y. Li, S. Peng, G. Lu and S. Li, Phys. Chem. Chem. Phys., 2013, 15, 7657-7665.

37 M. Shalom, S. Inal, D. Neher and M. Antonietti, Catal. Today, 2014, 225, 185-190.

38 F. He, G. Chen, Y. Yu, S. Hao, Y. Zhou and Y. Zheng, ACS Appl. Mater. Interfaces, 2014, 6, 7171-7179.

39 P. Niu, L. Zhang, G. Liu and H. M. Cheng, Adv. Funct. Mater., 2012, 22, 4763-4770. 